\title{
The launch of the Translational Perioperative and Pain Medicine
}

\author{
Renyu Liu, MD, PhD
}

On October 16, 1846, William T.G. Morton demonstrated ether anesthesia at the Massachusetts General Hospital and opened the giant gate to the modern anesthesia and surgery. This is great milestone in translational medicine in anesthesiology and perioperative science. However, it took over 100 years before mankind was able to use this compound for anesthetic usage. While the role of ether in the modern medicine has been replaced with safer drugs like sevoflurane and desfluraneetc, the mechanism underline such anesthetic effects remain elusive[1] and true neurological outcome effect is currently a hot topic of debate in aged brain and neonatal brain.[2,3]Further studies are warranted and newer anesthetics with minimal side effects are to be discovered and developed.

One of the greatest stories related to translational pain medicine is that of morphine. Natural morphine is from the opiate. While opiate has been used by human being back in third-century B.C., Morphine, the first active alkaloid as a modern medicine, was not extracted from the opium poppy plant until 1804 in Germany by Friedrich Sertürner, a 20-year-old pharmacy apprentice with limited education. His discovery did not raise immediate scientific and business interests. He himself became the true scientist and interpreneur to pursue and promote his discovery and business. 12 years later, he and his company marketed morphine in 1817 for analgesia, and as a "cure" for opium and alcohol addiction. It was recognized quickly that morphine itself is more addictive than opium or alcohol. Sertürner suffered from morphine addiction and chronic depression in his later years. He judged himself a failure in his quest to develop a safe and efficient analgesic formula, a way to kill pain without rendering the patient unconscious. The mechanism underline morphine effects was not revealed until 1973 when Candace Pert and Solomon H. Snyder discovered mu opioid receptor using radioactive naloxone binding studies at Johns Hopkins University School of Medicine.[4] The structures of opioid receptors were revealed using crystallography in 2012. [5-8] While it seems that the research related to opioids and opioid receptors had final conclusions, it is actually just the beginning of a golden age due to the a little more closer to the understanding the structural functional relationships. However, it is still unclear why opioid is addictive and scientists are still in searching safe pain medications, and the problem related opioid usage never abated and is actually soaring. The best medication available for pain management is probably still "morphine". Opioid is the "king" for pain management in the perioperative period and opioid is still the last resort for various persistent and severe pain.

The above stories are very inspiring for drug discovery in anesthesiology, perioperative medicine and pain medicine. It is important to note that despite anesthetics and opioids have served as medication for centuries, the mechanism related to both categories of medication are not yet elucidated. In the case of general anesthetics, no definitive target(s) is identified yet. While opioids have many notorious side effects including fatal respiratory depression and addiction, it 
is the dominant medication for severe pain especially in perioperative period. It is also important to note that the gap between the initial discovery and the final clinical usage is huge. There is no doubt that the new development of a new technology is much faster in recent years. However, the drug development and other new technology development are never such complicated as it was due to stricter regulations and many other barriers. Significant gap remains in many layers. New technology may pass through multiple "death valley" before it gains true life in clinical practice. Academic inventors are eager to get their works published in high impact journals for various purposes,i.e, funding and promotion. The institution may not want to submit the patent until the last minutewhen a paper related to the invention is accepted. The inventors worry about the non-transparent reviewing process since the invention is not patented yet. Almost all the scientific journals focus on academic achievement for a higher impact factor of the journals. Thus, many of the papers related to a new technology in its infancy are not easily get accepted in high end journals and it may take really very long time to get accepted with multiple revisions with the request of new data. The inventors generally lack of knowledge how to move forward even after the related paper is accepted and a patent is filed. The investors, entrepreneurs, and industries will not know anything about the availability of a novel technology until a related paper is published or a patent is open to the public. A platform for inventors, investors, policy regulators and industries is needed to reduce the gaps from novel technology to clinical practice. To build such platform, we are launching this journal trying to reduce the gaps for any innovative work in perioperative and pain medicine: Translational Perioperative and Pain Medicine. Our major focus is not to seek high impact factor at the cost of delaying development of novel technology or novel ideas in improving patient care, but to seek faster and higher success of business related to new technologies or a faster dissemination of the knowledge related to improving translational research, technology transfer, and improving clinical practice and patient care in perioperative and pain medicine.

The first issue of the journal will serve as a sample issue to indicate what kind of paper will be accepted which will include editorials, research papers, case report related to translational medicine,and reviews. I included two research works in our lab for two compounds that we are developing for potential novel clinical usage. These studies may be still in their infancy, but they demonstrate new potentials for these compounds, offers new direction for these who are trying to developing novel compounds for potential clinical usage.

One of the features of the journal is that we have significant wisdom contribution from industries. We have patent lawyers, technology transfer experts, and marketing experts on board. They will be available for consultation for our members. We hope that this will be an outstanding platform to merge science, business and clinical practice for perioperative and pain medicine. Your contribution and support are needed. If you think that you could contribute this effort, please feel free to contact us at 
References

1. Weiser BP, Woll KA, Dailey WP, Eckenhoff RG (2014) Mechanisms revealed through general anesthetic photolabeling. Current anesthesiology reports 4: 57-66.

2. Li XM, Su F, Ji MH, Zhang GF, Qiu LL, et al. (2014) Disruption of Hippocampal Neuregulin 1-ErbB4 Signaling Contributes to the Hippocampus-dependent Cognitive Impairment Induced by Isoflurane in Aged Mice. Anesthesiology 121: 79-88.

3. Creeley CE, Dikranian KT, Dissen GA, Back SA, Olney JW, et al. (2014) Isoflurane-induced apoptosis of neurons and oligodendrocytes in the fetal rhesus macaque brain. Anesthesiology 120: 626-638.

4. Pert CB, Snyder SH (1973) Opiate receptor: demonstration in nervous tissue. Science 179: 1011-1014.

5. Granier S, Manglik A, Kruse AC, Kobilka TS, Thian FS, et al. (2012) Structure of the delta-opioid receptor bound to naltrindole. Nature 485: 400-404.

6. Thompson AA, Liu W, Chun E, Katritch V, Wu H, et al. (2012) Structure of the nociceptin/orphanin FQ receptor in complex with a peptide mimetic. Nature 485: 395-399.

7. Wu H, Wacker D, Mileni M, Katritch V, Han GW, et al. (2012) Structure of the human kappa-opioid receptor in complex with JDTic. Nature 485: 327-332.

8. Manglik A, Kruse AC, Kobilka TS, Thian FS, Mathiesen JM, et al. (2012) Crystal structure of the microopioid receptor bound to a morphinan antagonist. Nature 485: 321-326. 